\title{
Desalination for preservation of murals by electromigration and regulated climate
}

\author{
I. Rörig-Dalgaard \\ Department of Civil Engineering, Technical University of Denmark, \\ Denmark
}

\begin{abstract}
The presence of salts is a threat against the preservation of cultural heritage, e.g. murals. The volume change from dissolved salt (ions) to precipitated salts results in crystallization pressure. This crystallization pressure can result in deterioration when the crystallization occurs underneath the surface, resulting in deterioration of the overlying material. The crystallization occurs most often in the evaporation zone, close to the surface, e.g. between the brick masonry and the lime layer with paintings.

In the present investigation it was aimed to improve the electromigration (ion transport in an applied electric field) desalination efficiency of a wall section with murals by regulation of the surrounding climate. The idea was to obtain a relative humidity $(\mathrm{RH})$ above the polluting salts deliquesce point $(\mathrm{NaCl} \sim 76 \%)$ to ensure the presence of dissolved salt (ions). A humidifier was used to create high relative humidity and the actual RH was followed with a hygrograph.

After two weeks of treatment with an applied electric DC field and regulated climate, the average chloride content for all brick and mortar samples was decreased from $0.6 \mathrm{wt} \%$ to $0.1 \mathrm{wt} \%$ and for all the brick samples from $0.53 \mathrm{wt} \%$ to $0.06 \mathrm{wt} \%$ on average.

The present experiment clearly showed the necessity of a relative humidity around the polluting salts deliquesce point in order to dissolute the salts before they can be transported in an applied electric DC field. Significant desalination was obtained in all the positions within the same range as seen in previous experiments with capillary saturated single bricks.
\end{abstract}

Keywords: desalination, electromigration, regulated climate, murals. 


\section{Introduction}

Cultural monuments are primarily dedicated to preserving historical credentials and they are especially appropriate for describing historical evolution. In addition, deterioration of cultural heritage is irrecoverable [1].

According to Tennikat et al. [2], the preservation of murals is one of the topics of main focus in relation to the preservation of monuments and historic buildings and the presence of salts is one of the most serious reasons for deterioration of murals.

Salt induced deterioration has been known for centuries and methods for desalination have been searched for. However, during the latest conference "Salt Weathering of Buildings and Stone Sculptures" in October 2008 in Copenhagen, a lack of efficient desalination methods was clarified. At present research is carried out with two different working principles: desalination by use of a poultice and by electromigration. In the first group (poulticing), a wet adhesive paste is applied to porous materials in order to draw out soluble salts with the main determining parameters: prewetting, drying of stone/poultice and adhesive properties of the poultice [3]. In the second group (electromigration), transport of dissolved salt (ions) occurs since the charged ions are attracted towards opposite charged electrodes in an applied electric field (termed electromigration).

In a previous investigation of a wall section with murals, significant reduction of the ionic content inside the wall section and accumulation of the extracted ions out into a removable poultice were shown. However, the desalination efficiency was high in some parts of the wall and low in other parts. It was likely that the variation in efficiency was related to the ease of moistening for the dissolution of the salts. Therefore, dissolution of the present salts to dissolved ions seemed to be the limiting factor [4].

In the present paper it was investigated whether use of a regulated climate, a method investigated in, e.g. [5], can result in a homogeneous high efficiency regardless of the ease of moistening. The aim was to obtain similar high desalination efficiency on a wall section as in previously experiments with electrochemical desalination of saturated single bricks [6].

\section{Electromigration}

Salts dissolve totally in water into positive and negative ions until the point of saturation. By application of an electric DC field, a positive and a negative electrode are established and the ions in the solution will be attracted to the electrode of opposite charge, and the ions will move in the electric field. This phenomenon is termed electromigration, figure 1 (left). By the use of electromigration a controlled ion transport is obtained in wet, porous materials, such as bricks and mortar. When transporting the damaging ions out of the contaminated structure (e.g. church vaults) into an accumulating layer surrounding the electrodes, the ions can be removed after the treatment is completed together with the accumulating layer and the contamination is removed. 

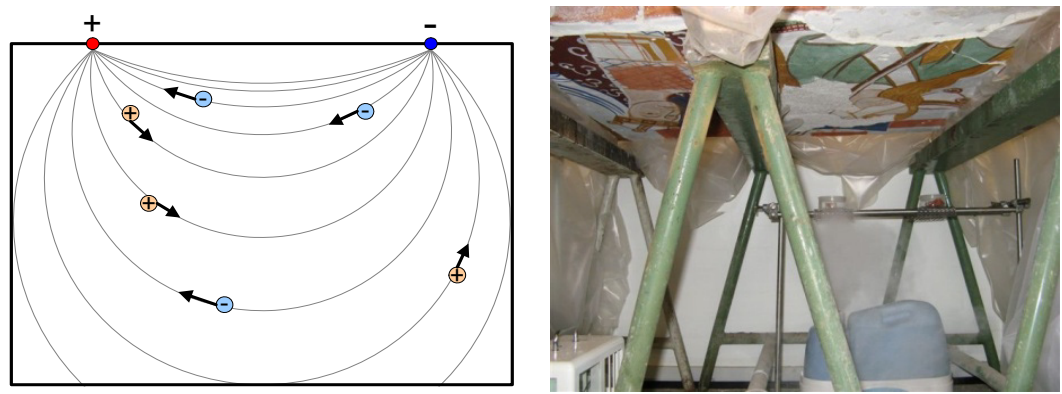

Figure 1: (Left) principal sketch of potential and current distribution in a vertical plane along the line of electrodes with ion migration freely, after [7]. (Right) the wall section seen from below.

\section{Experimental}

\subsection{The wall section}

The wall section used in the present work and in the previous work [4] was inherited from the Danish National Museum, where it was made in the summer 1994. Preparation of the wall section followed in several steps. The masonry consists of Falkenløwe bricks and mortar mixed from Rødvig Kulekalk and Kronhøj mortar sand (particle-sizes 0-5.0 $\mathrm{mm}$ ) in the ratio 1:3. The painting was made by a conservator from the Danish National Museum's conservation department. The wall section is shown in figure 1 (right). The sodium chloride solution was sprayed on from the back of the wall with a pollinator and the wall section was stored indoors for 14 years. Peeling of the lime layer with painting had occurred as expected due to ion transport towards the surface followed by salt precipitation and in the initial phase of the treatment before an electric field was applied, the relative humidity varied (see section 4.1) and resulted in accelerated peeling of the lime layer with painting occurred.

\subsection{Laboratory experiments}

During two weeks different initiatives was tried to obtain the needed microclimate below the wall section. Both water baths and a humidifier was placed below the wall section, in combination with varying practical initiatives and its ability to ensure the right climate was tested. For a detailed description, see section 4.1.

To isolate the relative humidity influence on the system, two small samples of bricks: one without salt (from a non contaminated part of the wall section) and one with salt were placed in small glasses for weighing close to the lower side of the wall section, see section 4.2.

Just before application of the electric DC field, $0.6 \mathrm{~L}$ distilled water was sprayed on the area consisting of 4 bricks and intervening mortar corresponding to maximum water content of $0.3 \mathrm{wt} \%$. The experiment included two sets of 
parallel working electrodes. A current strength of $39 \mathrm{~mA}$ was applied through electrodes with the length of $20 \mathrm{~cm}$ (corresponding to $2.0 \mathrm{~mA} / \mathrm{cm}$ electrode) in two circuits and the corresponding voltage followed (see section 4.3). The anodes were $3 \mathrm{~cm}$ wide oxide coated titanium meshes and the cathodes $5.5 \mathrm{~cm}$ wide stainless steel meshes. The distance between anode 1 and cathode 1 , anode 2 and cathode 2 was approximately $12 \mathrm{~cm}$. The poultice was placed in rectangular forms (L: $19 \mathrm{~cm} \times \mathrm{D}: 5.5 \mathrm{~cm} \times \mathrm{H}: 3.5 \mathrm{~cm})$ to ensure the right amount of poultice and ease in the calculation of extracted chloride and sodium. The forms were placed perpendicular to the length of the bricks and below the full length of the electrodes, see figure 3 (left + right). During the treatments first week the poultices dried too fast and around $50 \mathrm{~mL}$ in total was sprayed on the four poultices every day. For the second week, poultices with higher initial water contents were used and additional moistening or any other kind of daily intervention was unnecessary.
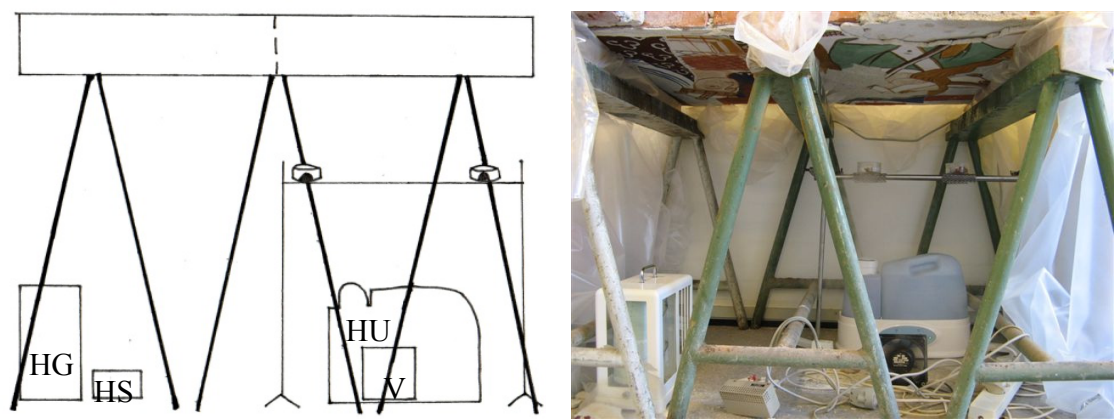

Figure 2: (Left) principal sketch of the setup. HG is the hydrograph, HS a hygrostat connected to a humidifier (HU), $\mathrm{V}$ is a ventilator and $\mathrm{G}$ is glasses for weighing with brick samples. (Right) picture of the setup.

\subsection{Sampling description}

For determination of the initial salt content, drilling samples $(10 \mathrm{~mm})$ were taken from bricks in positions 1, 2, 5 and 6 and from the mortar in position 4, see figure 3 (left). A hole was drilled in the entire depth, in the three intervals from the back side of the wall (the side without paintings): 0-5 cm (termed top), 5-10 $\mathrm{cm}$ (termed middle) and 10-15 $\mathrm{cm}$ (termed bottom). The drilling samples before and after treatment were made close to each other. Furthermore, spot checks of the poultice from the electrode units were made by extraction of around $5 \mathrm{~g}$ from the poultice from the middle of each brick.

\subsection{Analytical}

Water content in the brick powder was determined after drying of the samples at $105^{\circ} \mathrm{C}$ until equilibrium (obtained after approximately 24 hours). In relation to 

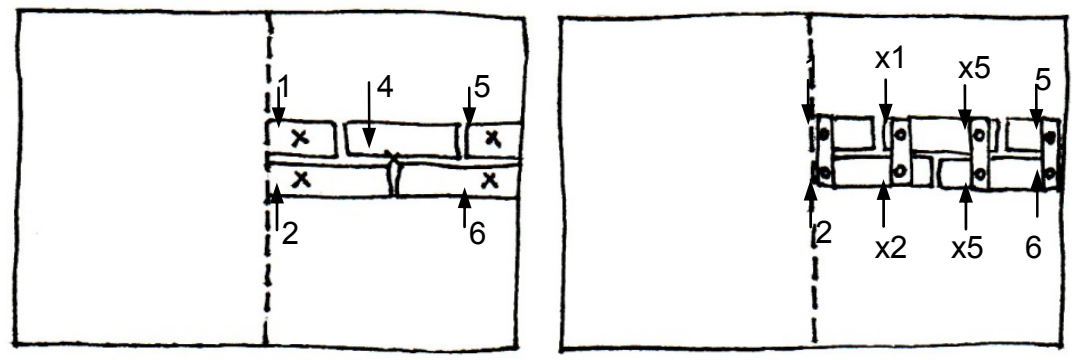

Figure 3: An overview of: (left) the sample positions; (right) taken spot checks from the poultices, 1 and 2 are from the anode poultice in circuit $1, \mathrm{x} 1$ and $\mathrm{x} 2$ from the cathode poultice in circuit $2, \mathrm{x} 5$ and x6 from the anode poultice in circuit 2 and 5 and 6 from the cathode poultice in circuit 2 .

electromigration only soluble ions are of interest. The supplied and domination ions $\mathrm{Cl}^{-}$and $\mathrm{Na}^{+}$are soluble too, and extractions with the drilling samples (around $5 \mathrm{~g}$ ) dry brick and mortar powder in $12.50 \mathrm{~mL}$ distilled water for 24 hours undisrupted agitation was carried out. The $\mathrm{pH}$ was measured with electrodes directly in the suspensions after extraction. After mixing 1-5 ml (dependent of the chloride concentration to obtain values within the apparatus row of standard) of the suspension with $40 \mathrm{~mL}$ distilled water and $1 \mathrm{~mL} 1 \mathrm{M}$ $\mathrm{HNO}_{3}$ the chloride content was measured with a titrator (Metrohm 716 DMS Titrino). Filtration of the suspensions through $0.45 \mu \mathrm{m}$ filter paper was carried out before measurement of the sodium content with an atomic absorption spectrophotometer.

\section{Results and discussion}

\subsection{The relative humidity}

The previous experiment with the wall section was carried out during the winter in the dry laboratory (8-22 January 2008) [4]. However, the actual relative humidity was unfortunately not monitored. During the previous investigations, the dissolution of the nucleated salts was assumed to be the limiting factor. Only in short periods when distilled water was sprayed on the surface and before equilibrium with the surrounding climate came into existence the nucleated salts were dissolved. The present experiment was also carried out in a period with low RH in the laboratory (11 February-20 March 2009).

To obtain dissolution of the present salt $\mathrm{NaCl}$ with a deliquesce point of $76 \%$ $\mathrm{RH}$, a relative humidity above $76 \% \mathrm{RH}$ was needed. Different initiatives were tried during 2 weeks and on the $14^{\text {th }}$ day were a satisfying microclimate was obtained the electric DC field was applied during the following two weeks. The actual measured relative humidity is shown in figure 4 . 


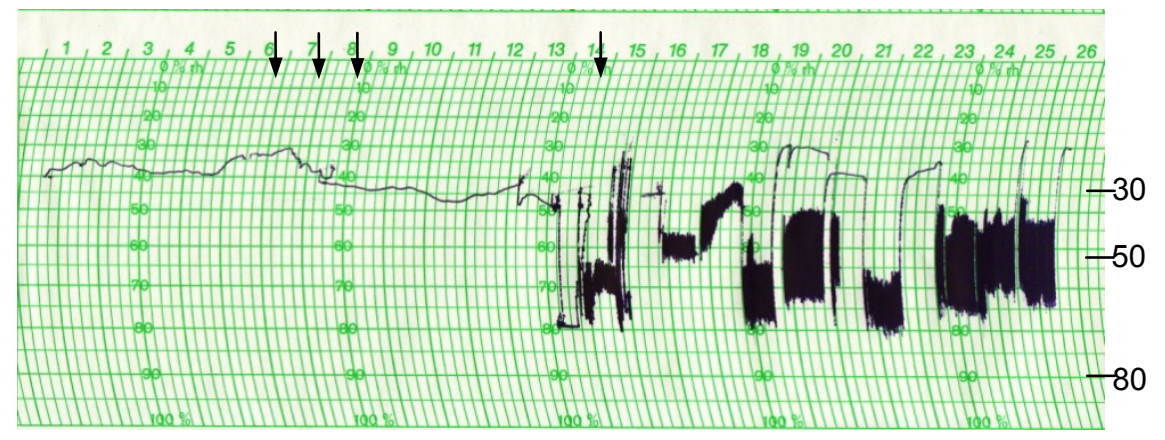

Figure 4: $\quad$ Monitoring of the relative humidity below the wall section. Day 16 the actual climate in the laboratory, $6^{\text {th }}$ day three boxes with distilled water was introduced, $7^{\text {th }}$ day cowering with plastic, $8^{\text {th }}$ day introduction of a ventilator, $14^{\text {th }}$ day introduction of a humidifier.

From day 1-6, the hydrograph was placed below the wall section to monitor the actual climate in the laboratory $(30<\% \mathrm{RH}<40)$, on the $6^{\text {th }}$ day three boxes with distilled water was placed below the wall section $(\mathrm{RH} \sim 35 \%)$. On the $7^{\text {th }}$ day the wall section was covered with thick plastic $(0.140 \mathrm{~mm}+/-0.001 \mathrm{~mm})$. On the $8^{\text {th }}$ day a ventilator was introduced below the wall section to ensure a homogenously climate. From the $8^{\text {th }}$ to the $13^{\text {th }}$ day the relative humidity only increased to around 50\% which was significant below the needed $76 \% \mathrm{RH}$ and the three boxes with distilled water were removed. Instead on the $14^{\text {th }}$ day a humidifier was placed below the wall section and within one hour a relative humidity around $80 \% \mathrm{RH}$ was obtained and the humidifier was working until the treatment was ended. Additional a hygrostat was connected to the humidifier after some days in order to maintain the most stable relative humidity. With the humidifier and the hygrostat it was possible to maintain a relative humidity below the wall section between 50 and $80 \% \mathrm{RH}$. This rather high variation in relative humidity was probably caused by the humidifier it selves. The humidifier did not supply moisture continuously, contrary it seemed like first when the RH dropped below 50\% RH moisture was supplied to the surrounding climate.

Sodium chloride deliquesce point is almost independent of the temperature [8] and the actual seen deviations from 17 to 23 are therefore limited determining and not shown here.

\subsection{The effect of the regulated climate on small brick samples}

Different relative humidities were present during the investigated 4 weeks. The glasses for weighting with brick samples was weighed at different relative humidities and on basis of this the corresponding water content was calculated, table 1 . 
Table 1: Changes in the equilibrium moisture content at varying relative humilities, with and without salts.

\begin{tabular}{|l|c|c|c|c|}
\hline Sample & $30 \% \mathrm{RH}$ & $40 \% \mathrm{RH}$ & $70 \% \mathrm{RH}$ & $80 \% \mathrm{RH}$ \\
\hline Without salt & 0 & 0 & 1.3 & 6.8 \\
\hline With salt & 0 & 0.1 & 9.0 & 11.5 \\
\hline
\end{tabular}

The moisture content was calculated to zero at 30\% RH. In the literature [9] the actual water content approximately $0.3 \mathrm{wt} \%$ at $30 \% \mathrm{RH}$. Also at a $\mathrm{RH}$ around $40 \%$ the corresponding equilibrium moisture content was close to zero. At $70 \%$ $\mathrm{RH}$ the sample with salt had a high water content also significant higher water content than the sample without salt. At $80 \% \mathrm{RH}$ both the sample with and without had a high brick water content but the sample with salt had a significant higher content that the sample without salt.

At 30 and $40 \% \mathrm{RH}$ white precipitated salt was visible at the surface of the sample with salt; at $70 \% \mathrm{RH}$ the salts were partly precipitated, whereas at $80 \%$ $\mathrm{RH}$ no visible salts were present at the surface.

This indicates that the present salts are precipitated, non charged salts at $\mathrm{RH} \leq$ $40 \%$ whereas at $\mathrm{RH} \geq 80 \%$ most likely present as dissolved charged ions. These findings are based on approximated measurements and additional it was not tested at which specific relative humidity the salts dissolved to ions but it most likely occurred at $\mathrm{RH}=76 \%$ as described in the literature e.g. [8].

\subsection{The voltage during the treatment}

To follow the current distribution and thereby indirectly the actual transport of ions the voltage was followed during the 2 weeks treatment, figure 5. By presence of more than one set of electrodes, the electric field can influence on each other.

In the first week (0-10.000 hours) the lowest voltage was in circuit 1 . However, the voltage increased significantly within 24 hours, the poultices seemed hart and dry and in order to reduce the total voltage in both circuits distilled water $(70 \mathrm{~mL}$ in total for both circuits) was sprayed on the anode and cathode poultice to reduce the resistance in the poultices. The result was an instantaneous drop in the voltage followed by continuously increase in the voltage until the new addition of distilled water the next day.

The poultices were changed after 1 week (10.000 hours) with new poultices with higher water contents. The higher water content corresponded to the added water content to the poultice for one day the week before. The higher water content in the new poultice resulted in a release of water in excess to the brick masonry, which visually afterwards seemed wetted.

The measured values in figure 5 (the dotted line) indicate a changed development in the voltage between values below $40 \mathrm{~V}$ and values above $40 \mathrm{~V}$. By comparison of the obtained final ionic contents in the wall section and the extracted contents to the poultices in the positions corresponding to circuit it could be argued that almost total extraction of the pollution ion had occurred and resulted in the increasing voltage after 18.000 hours (22 days). 


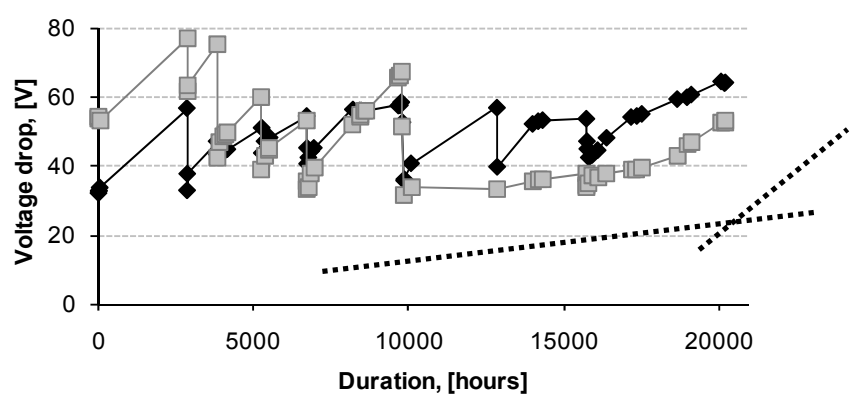

Figure 5: The voltage drop during the treatment. The measured values are shown for: Circuit 1— Circuit 2. The black dotted line shows the tendency for the development in the voltage drop in the second week in circuit 2 .

\subsection{Desalination}

The effect of the treatment was partly evaluated on changes in ionic content in the wall section and partly on the extracted ions into the removable poultice.

\subsubsection{Chloride and sodium contents in the wall section}

The ionic contents (chloride and sodium) in the wall section before and after treatment are shown in figure 6.

Comparison of the tendencies for the ion profiles between the measured chloride and sodium before treatment (solid lines) are similar which likely reliability of the measurements.

In average the sodium content was reduced from $0.28 \mathrm{wt} \%$ to $0.04 \mathrm{wt} \%$ or below. The chloride content was in average in the brick samples reduced from $0.60 \mathrm{wt} \%$ to $0.10 \mathrm{wt} \%$. The average chloride content after the 2 weeks treatment was $0.14 ; 0.07 ; 0.28 ; 0.02 ; 0.00$ in position $1,2,4,5,6$ respectively.

The total decrease in the chloride content was in the same range as in the previous single brick experiments [10], however a little higher. This could indicate that the measured effect is a combination of both the applied electric DC field and also influenced of the evaporation induced ionic transport as a consequence of the high $\mathrm{RH}(50-80 \% \mathrm{RH})$ underneath the wall section and the low RH (30-40\% RH) above the wall section.

\subsubsection{Chloride and sodium extractions}

To assess whether redistribution or reel desalination had occurred during the 2 weeks application of the applied electric DC field, the amount of extracted pollution ions out into the poultice was measured for both of the pollution ions: chloride and sodium, figure 7.

The extracted chloride was between $0.9 \mathrm{~g}$ and $3.9 \mathrm{~g}$ per week. In the previous treatment [4], the best obtained result was $3.5 \mathrm{~g}$ in 2 weeks with only half the 

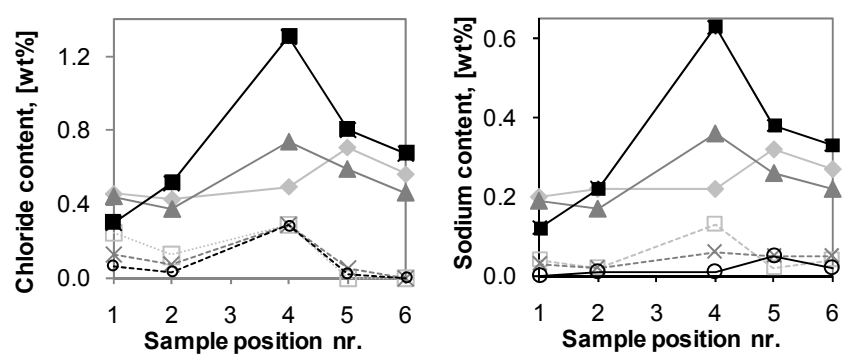

Figure 6: Chloride and sodium contents in positions 1,2,4,5 and 6. The solid lines connect the initial measured contents before treatment and the dotted lines connect the final contents after treatment. The black dots are from the top samples, middle gray from the middle samples and the bright gray from the bottom samples closest to the paintings.

applied current as in the present work which makes the results comparable. This value was only obtained in one point were moistening could occur from several surfaces. Similar high extractions was obtained for $1 \_1 \mathrm{~W}, 1 \_2 \mathrm{~W}, \mathrm{x} 5 \_2 \mathrm{~W}$ and presumably also for $\mathrm{x} 6 \_2 \mathrm{~W}$ if total extraction had not occurred and the remaining extractions were also high compared with the extractions obtained in the previous experiments without regulated climate. In previous single brick experiments under ideal conditions (capillary saturated, $1.0 \mathrm{wt} \%$ chloride) electrokinetic extraction between 3.8 and 5.6 was obtained per brick with the same current consumption [10].

On basis of the voltage measured during the treatment, circuit 1 was most stable during the first week whereas in the second week, circuit 2 was most stable. Therefore the higher extractions should be expected for $1 \_1 \mathrm{~W}$ and 2 _ $1 \mathrm{~W}$ than 1_2W and 2_2W, however only small differences occurred. Similar higher extractions for $\times 5 \_2 \mathrm{~W}$ and $\mathrm{x} 6 \_2 \mathrm{~W}$ than $\mathrm{x} 5 \_1 \mathrm{~W}$ and $\mathrm{x} 6 \_1 \mathrm{~W}$ should be expected. The measured extraction in $\times 5 \_2 \mathrm{~W}$ is significantly higher than in $\mathrm{x} 5$ - $1 \mathrm{~W}$ as expected. Contrary to the expectations the extractions measured in $\times \overline{6}+2 \mathrm{~W}$ is significantly lower than in $\mathrm{x} 6 \_2 \mathrm{~W}$, however, the chloride content of $0.00 \mathrm{wt} \%$ in position 6 below the poultice after ended treatment (see section 4.4.1) accounts for this lower rate and the also suddenly voltage increasing during the end of the treatment supports the reason for the unexpected low extraction in $\mathrm{x} 6 \_2 \mathrm{~W}$. The chloride extractions from position $\mathrm{x} 5$ and $\mathrm{x} 6$ in the first week were the total resistance in the circuit was non optimal are within the same range.

To likely the accuracy of the extracted contaminating ions, the sodium content was measured. For the comparison the measured chloride content was recalculated to sodium content by taking their differences in molar mass into account and these calculated values were compared with the measured values for sodium, shown in figure 8.

The measured values for sodium and the calculated values of sodium based on the chloride measurement next to position 1 and 2 correspond satisfying to each other. Contrary, high deviations are present between the measured and the 


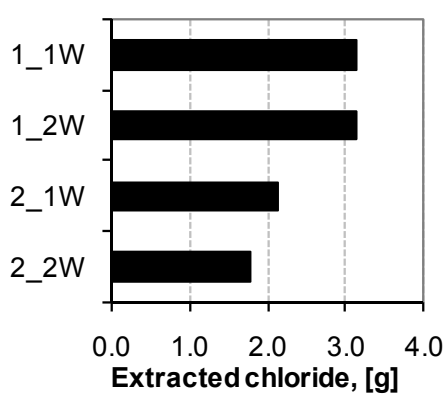

(a)

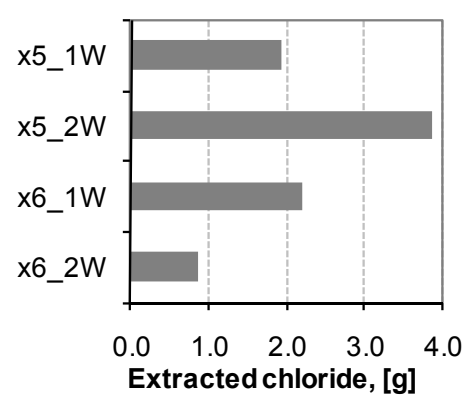

(b)

Figure 7: $\quad$ Extracted (a) chloride in circuit 1; (b) chloride in circuit 2. The first number and letter is related to the sample position where without " $x$ " means just above the position and with " $x$ " means in the same circuit. The number and letter after the underscore shows whether the values are after 1 week or 2 weeks.
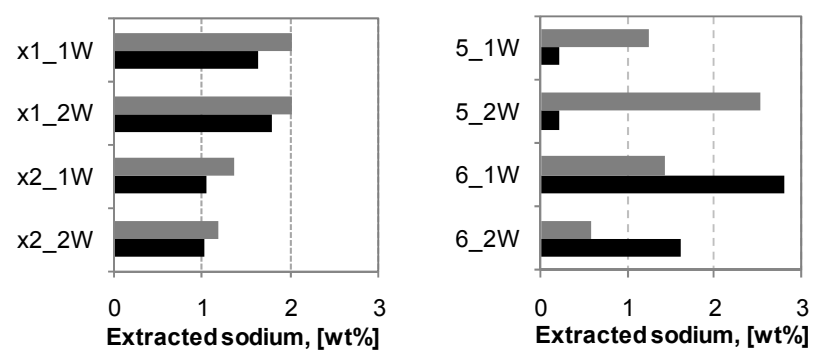

Figure 8: $\quad$ Extracted (left) sodium in circuit 1; (right) sodium in circuit 2. The black values are measured and the gray values are calculated on basis of the measured chloride contents. The first number and letter is related to the sample position where without " $\mathrm{x}$ " means just above the position and with " $x$ " means in the same circuit. The number and letter after the underscore shows whether the values are after 1 week or 2 weeks.

calculated values above position 5 and 6 , and for this reason were all four measurements redone, however without any different result. The measured values above position 5 were surprising low. Above position 6 , the ratio between calculated and measured sodium was the same after 1 and 2 weeks.

\subsection{Remark related to the previous treatment}

The effect of the climate was estimated by comparison with the previous investigation [4]. On basis of the present investigation of the influence of the climate on the dissolution of salts, it seems not surprising that only a limited effect of the applied electric DC field was seen in the previous investigation 
without controlled climate. The simple dissolution tests in section 4.2 showed a significant increase in the equilibrium water content at high relative humidity's $(>70 \%)$ and they also showed significant higher water content of the sample with salt which ease the transport of ions in an applied electric field.

\section{Conclusion}

Optimization of desalination from a dry wall section was carried out by use of regulation and monitoring of the microclimate, monitoring of the voltage, a simple salt dissolution test at different relative humidity's and adjustment of the poultices for use on dry constructions. On basis of the simple salt dissolution tests the relative humidity's effect on the dissolution of contaminating salt and the salts ability to local salt induced increase in the water content was seen. It was seen that a RH around the contaminating salts deliquesce point is necessary to dissolve the present salts to transport them in an applied electric DC field. Through the monitored voltage during the electrokinetic treatment it was seen that an adjustment of poultice for use on this dry construction was needed to ensure a stable electric circuit were no daily adjustments were necessary. During the electrokinetic treatment and after the treatment no visual changes occurred of the painted layers. The result of the 2 weeks application of an electric DC field and regulated climate was a reduction in both the chloride and sodium content in all positions. Additional reel desalination instead of redistribution occurred in all positions, since the contaminating ions were transported out into the removable layer. The present work shows electrokinetic desalination as an efficient method on a dry brick masonry wall section.

\section{Acknowledgements}

The Augustinus foundation is acknowledged for their financial support. Staffan Svensson and Kurt Kielsgaard Hansen are acknowledged for their valuable help with and input to the microclimate.

\section{References}

[1] Christiane Segers-Glocke, Vorwort. Editor: Christiane Segers-Glocke Hameln: Niemeyer, 1994. In: Forschungsprojekt Wandmalerei-Schäden: ein Förderprojekt des Bundesministers für Forschung und Technologie; Schlussbericht zu den interdisziplinären Ergebnissen/ Niedersächsisches Landesverwaltungsamt, Institut für Denkmalpflege Arbeitshefte zur Denkmalpflege in Niedersachsen 11. pp. 5-6, 1994.

[2] Tennikat, M., Schad, J., Juling, H., Gülker, G., Hinsch, K.D., Leonhardt, C., Untersuchungen zum Einfluss einer Warmluftheizung auf Wandmalerieschäden in der Kirsche St. Laurentii auf Föhr. In: Bundesministerium für Forschung und Technologie, BMFT- 
82 Structural Studies, Repairs and Maintenance of Heritage Architecture XI

Jahresforschrittband 1993. Band 6, 1994 Steinzerfall-Steinkonservierun, pp. 307-318, 1994.

[3] Bourguignon, E., Bertrand, F., Bourges, A., Coussot, P., Shahidzadeh-Bonn N., Poultice characterization and MRI study of desalination of model stones. In Proceedings: "Salt Weathering on Buildings and Stone Sculptures”, 22-24 October 2008, Copenhagen, Denmark, pp. 329-339, 2008.

[4] Rörig-Dalgaard, I., Ottosen, L.M., Christensen, I.V., Desalination of a wall section with murals by electromigration. In Proceedings: "Salt Weathering on Buildings and Stone Sculptures”, 22-24 October 2008, Copenhagen, Denmark, pp. 361-371, 2008.

[5] Larsen, P.K., Desalination of painted bricks vaults. Ph.D. thesis. Technical University of Denmark, Department of Structural Engineering and Materials, Appendix A, 1999.

[6] Rörig-Dalgaard, I., Ottosen, L.M., Preservation of murals on salt loaded masonry vaults by electromigration. In Proceedings: "Structural Studies, Repairs and Maintenance of Heritage Architecture X” pp. 309-318, 2007.

[7] van Nostrand, R.V. Cook, K.L., Interpretation of Resistivity Data, Geological Survey Professional paper 499. United States Government Printing Office, 1966

[8] Lubelli, B.A, Sodium chloride damage to porous building materials. Ph.D thesis. TU Delft, The Nederland, p. 7.

[9] Gottfredsen, F.R., Nielsen, A., Bygningsmaterialer - Grundlæggende egenskaber (In Danish). Building materials - basic properties. Polyteknisk Forlag. p. 226, 1997.

[10] Rörig-Dalgaard, I., Ottosen, L.M., Development of a poultice for electrochemical removal from bricks - Effects and side effects. Submitted. 